\title{
A nonsense mutation of bone morphogenetic protein-15 (BMP15) causes both infertility and increased litter size in pigs
}

Gabriele Flossmann ${ }^{1 *}$ (D), Christine Wurmser ${ }^{1}$, Hubert Pausch ${ }^{1,2}$, Amabel Tenghe $^{1}$, Jörg Dodenhoff ${ }^{3}$, Günther Dahinten ${ }^{3}$, Kay-Uwe Götz ${ }^{3}$, Ingolf Russ ${ }^{4}$ and Ruedi Fries ${ }^{1}$

\begin{abstract}
Background: Atypical external genitalia are often a sign of reproductive organ pathologies and infertility with both environmental or genetic causes, including karyotypic abnormalities. Genome-wide association studies (GWAS) provide a means for identifying chromosomal regions harboring deleterious DNA-variants causing such phenotypes. We performed a GWAS to unravel the causes of incidental cases of atypically small vulvae in German Landrace gilts.

Results: A case-control GWAS involving Illumina porcine SNP60 BeadChip-called genotypes of 17 gilts with atypically small vulvae and 1818 control animals (fertile German Landrace sows) identified a significantly associated region on the $\mathrm{X}$-chromosome $\left(P=8.81 \times 10^{-43}\right)$. Inspection of whole-genome sequencing data in the critical area allowed us to pinpoint a likely causal variant in the form of a nonsense mutation of bone morphogenetic protein15 (BMP15; Sscrofa11.1_X:g.44618787C>T, BMP15:p.R212X). The mutant allele occurs at a frequency of $6.2 \%$ in the German Landrace breeding population. Homozygous gilts exhibit underdeveloped, most likely not functional ovaries and are not fertile. Male carriers do not seem to manifest defects. Heterozygous sows produce $0.41 \pm 0.02$ $\left(P=4.5 \times 10^{-83}\right)$ piglets more than wildtype animals. However, the mutant allele's positive effect on litter size accompanies a negative impact on lean meat growth.

Conclusion: Our results provide an example for the power of GWAS in identifying the genetic causes of a fuzzy phenotype and add to the list of natural deleterious BMP15 mutations that affect fertility in a dosage-dependent manner, the first time in a poly-ovulatory species. We advise eradicating the mutant allele from the German Landrace breeding population since the adverse effects on the lean meat growth outweigh the larger litter size in heterozygous sows.
\end{abstract}

Keywords: Swine, German landrace, GWAS, Fertility, BMP15

\footnotetext{
* Correspondence: gabriele.flossmann@tum.de

${ }^{1}$ Lehrstuhl für Tierzucht, Technische Universität München, Freising, Germany

Full list of author information is available at the end of the article
}

(c) The Author(s). 2021 Open Access This article is licensed under a Creative Commons Attribution 4.0 International License, which permits use, sharing, adaptation, distribution and reproduction in any medium or format, as long as you give appropriate credit to the original author(s) and the source, provide a link to the Creative Commons licence, and indicate if changes were made. The images or other third party material in this article are included in the article's Creative Commons licence, unless indicated otherwise in a credit line to the material. If material is not included in the article's Creative Commons licence and your intended use is not permitted by statutory regulation or exceeds the permitted use, you will need to obtain permission directly from the copyright holder. To view a copy of this licence, visit http://creativecommons.org/licenses/by/4.0/ The Creative Commons Public Domain Dedication waiver (http://creativecommons.org/publicdomain/zero/1.0/) applies to the data made available in this article, unless otherwise stated in a credit line to the data. 


\section{Background}

A number of German Landrace sows with atypically small vulvae have been recently observed on several Bavarian farms. Most of the sows turned out to be anoestrous or, when they showed signs of oestrus, insemination was not possible due to problems in introducing the artificial insemination device. Usually, more than one gilt of a litter was affected by the abnormality but not all. Although environmental factors such as mycotoxin intoxication or nutritional deficiencies could not be ruled out to cause the observed condition, we presumed a genetic etiology. Abnormal external genitalia are often seen in the context of intersexuality. Karyotypically female pigs $(18, \mathrm{XX})$ have been reported with phenotypes ranging from complete external masculinization with testes to an external female appearance with enlarged clitorises, testes, and ovotestes [1]. A genomewide association study pointed to the causal implication of SOX9 in the sex-reversal phenotype of these SRYnegative XX pigs [2]. To explore possible genetic causes of the newly observed phenotype of abnormal female genitalia we also undertook a genome-wide case-control study that led us to a nonsense mutation in BMP15, most likely the cause for the abnormality in homozygously affected animals but also for increased litter size in heterozygous sows.

\section{Results}

\section{Genome-wide association study}

We had access to tissue samples of 43 German Landrace gilts, considered as affected based on their abnormally small vulvae. The 43 affected animals originated from 21 litters of 20 sows and 11 known boars and were from four breeding units; the sire of one litter was unknown (Additional file 1). Seventeen affected individuals were considered as cases in a genome-wide association study (GWAS) with 1818 fertile sows from the Bavarian German Landrace population as controls. All sows included in the GWAS were genotyped on the Illumina Porcine SNP60 BeadChip. Association testing revealed a cluster of 18 significantly associated SNPs $(P<9.87 \times$ $10^{-7}$ ) between $38.6 \mathrm{Mb}$ and $108.7 \mathrm{Mb}$ on the $\mathrm{X}$ chromosome (Fig. 1a). The most significant SNP $(P=$ $\left.8.81 \times 10^{-43}\right)$ on the X-chromosome $(\mathrm{rs} 328794518,88$, 499,366 bp, Sscrofa11.1 assembly) was an intron variant in the ENSSSCG00000012566 gene. We considered significantly associated, scattered SNPs on other chromosomes as artifacts due to the inflation of significant signals $(\lambda=1.26$, Fig. $1 \mathrm{~b})$.

\section{Identification of the underlying mutation by analyzing whole-genome re-sequencing (WGS) data}

Re-sequencing data of 42 pigs (22 German Landrace and 20 Piétrain boars and fertile sows) were available for identifying possible causal variants. The sire of eight affected gilts was among the 42 sequenced pigs. We located 828 coding variants within the associated region (38.6 Mb to $108.7 \mathrm{Mb})$, of which 366 were missense mutations, 30 were frameshift variants, and five were nonsense-mutations. The sire of the affected gilts was hemizygous for one of the five nonsense-mutations. This nonsense-mutation, with no previous reports, is a $C$ to $\mathrm{T}$ substitution in the second exon of BMP15 (Sscrofa11.1 X:g.44618787C $>$ T, NP_001005155.2:p.R212X). In addition to the sire of affected gilts, two German Landrace boars and one German Landrace sow were carriers of the nonsense-mutation (Additional file 2). None of the Piétrain pigs carried the mutation.

\section{Validation of the nonsense mutation in BMP15}

All 22 German Landrace pigs with whole-genome sequences were genotyped by Sanger sequencing to confirm the mutation technically (Additional file 3). Complete concordance with WGS derived genotypes corroborates the technical validity of the variant. Next, we genotyped 43 sows, assessed by the farmers to exhibit
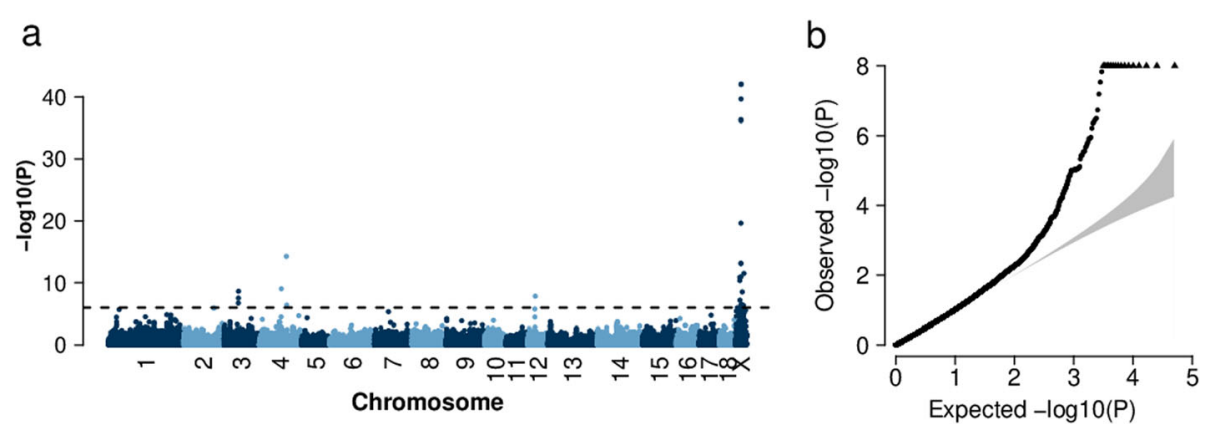

Fig. 1 Genome-wide association study for atypically small vulvae in 1835 German Landrace sows. Manhattan plot (a) representing the association of 50,649 SNPs with atypically small vulvae in the German Landrace population. The dots above the dashed line represent SNPs with $P$ values less than $9.87 \times 10^{-7}$ (Bonferroni corrected significance threshold) and Quantile-quantile plot (b). The grey shaded area represents the $95 \%$ concentration band under the null hypothesis of no association. Triangles represent SNPs with $P$ values less than $9.87 \times 10^{-7}$ 
small vulvae, 29 full siblings with normal vulvae, and 4869 fertile sows, using either a KASP ${ }^{\mathrm{m} w}$ genotyping assay or a customized version of the Illumina Porcine SNP60 BeadChip containing the p.R212X variant of BMP15. Of the 43 sows with abnormal vulvae, 36 were homozygous for the $\mathrm{T}$ allele, three were heterozygous $(\mathrm{C} / \mathrm{T})$, and four were homozygous for the wild type allele $(C)$. Of the seventeen animals that we considered as cases in the GWAS, only eleven turned out to be homozygous for the mutant allele; three animals where heterozygous and three animals were homozygous for the wildtype allele. None of the 4869 fertile sows and none of the 29 unaffected full siblings of affected gilts were homozygous for the $\mathrm{T}$ allele (Table 1 ). The frequency of the $\mathrm{T}$ allele in the 4869 fertile sows was 0.062 .

While fertile sows and gilts that were classified to have normal-sized vulvae were not homozygous for the nonsense mutation of BMP15, seven of the 43 presumably affected gilts carried one or two wild type alleles. This finding is not compatible with the hypothesis of the nonsense mutation causing small vulvae. However, assessing the size of the vulva is subjective, and the discrimination between affected and unaffected animals is prone to error. On the other hand, if an animal's status is assessed based on the objective criterion of fertility (i.e., an animal having one or more litters), the hypothesis that the nonsense mutation of BMP15 causes underdeveloped external sexual organs and consequent infertility remains valid.

\section{Effect of the mutation on reproductive organs}

The initial phenotyping consisted of on-farm observations of gilts with underdeveloped vulvae. A more thorough assessment of the phenotype in the field turned out to be impracticable. Therefore, we acquired two gilts that were heterozygous for BMP15:p.R212X and mated them on an experimental farm with a boar carrying the mutation. One of the resulting litters consisted of male piglets only, while the other litter consisted of thirteen piglets, ten of them female. Of the female piglets, five were homozygous for the $\mathrm{T}$ allele, and five were heterozygous $(C / T)$. At the age of 6 months, eight of the ten female pigs (five homozygous and three heterozygous) were slaughtered, and their uteri and ovaries resected. The uterus horns of the homozygous animals were considerably smaller, specifically less voluminous (Fig. 2a, b, c) or less coiled (Fig. 2d and e) than those of their heterozygous full siblings (Fig. 2f, g, h). The differences in the appearance of the ovaries were even more pronounced. As shown in Fig. 3, the ovaries of homozygous gilts (Fig. 3a to e) did not exhibit follicles, whereas multiple follicles were evident in the ovaries of their heterozygous full siblings (Fig. 3f to $h$ ). Besides the morphologically assessed underdevelopment of the ovaries and uteri, there may also be functional deficits as indicated by cysts in two homozygously affected gilts (Fig. $3 \mathrm{~d}$ and e). It is noteworthy that the two gilts with cysts exhibit uterus horns that are more voluminous (Fig. 2d and e) than those of their homozygous siblings (Fig. 2a, b, c), but less coiled than those of their heterozygous siblings (Fig. $2 \mathrm{f}$ to h).

\section{Effects of the mutation on fertility and other economically important breeding traits}

Nonsense and missense mutations of BMP15 increase ovulation rate in heterozygous ewes but cause infertility in ewes that are homozygous for the mutant allele (first reported by Galloway et al. (2000) [3]). Therefore, we analyzed the effects of the BMP15 nonsense mutation (i. e., the T-allele) on fertility, measured as the number of live-born piglets, and several other economically important traits, most of them growth-related. Since genotypes were not available for all sows with breeding values, we derived the T-allele dosage based on the parents' genotypes and the $\mathrm{T}$-allele frequencies in male and female animals. A total of 5263 genotyped parents were available (4263 C/C-sows, $606 \mathrm{C} / \mathrm{T}$-sows, $367 \mathrm{C}$-boars, and $27 \mathrm{~T}$-boars; $\mathrm{T} / \mathrm{T}$-females cannot be parents as they are infertile). The frequency of the $\mathrm{T}$-allele amounts to $\mathrm{q}_{\mathrm{m}}=$ 0.069 in male, and $\mathrm{q}_{\mathrm{f}}=0.062$ in female parents. Table 2 lists the expected dosages and Table 3 the number of animals in each dosage group.

We applied a linear regression model to estimate the effect of the T-allele of the BMP15 nonsense mutation on breeding values (Table 4).

The T-allele has a significantly positive effect on the number of live-born piglets (+ 0.41 piglets). Thus, the $B M P 15$ mutation increases the litter size, probably as a result of an increased ovulation rate, and causes infertility in a dosage-sensitive manner (one T-allele increases the litter size, two T-alleles cause infertility). The positive effect of the BMP15 mutation on litter size is

Table 1 Genotypes of the p.R212X variant of BMP15 for 4941 German Landrace sows

\begin{tabular}{llll}
\hline Genotype & Sows with small vulvae & Full siblings with normal vulvae & Fertile German Landrace sows \\
\hline C/C (ref/ref) & 4 & 0 & 4263 \\
$\mathbf{C} / \mathbf{T}$ (ref/alt) & 3 & 29 & 606 \\
$\mathbf{T} / \mathbf{T}$ (alt/alt) & 36 & 0 & 0 \\
$\mathbf{N}$ sows & 43 & 29 & 4869 \\
\hline
\end{tabular}




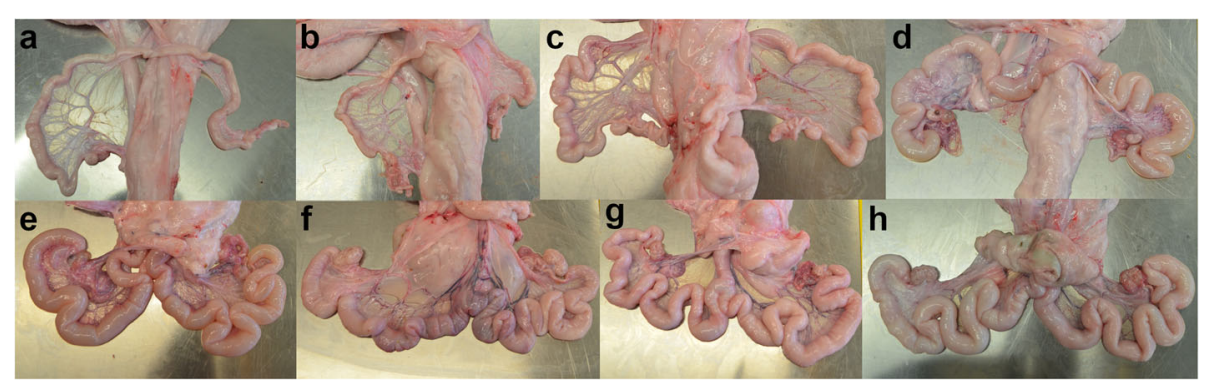

Fig. 2 Uteri of 8 fullsibs at the age of 6 months. Uteri of fullsib gilts from the mating of a sow with genotype C/T of Sscrofa11.1_X:g.44618787C>T (BMP15:R212X) and a boar carrying the T allele. Pictures $\mathbf{a}$ to $\mathbf{e}$ show uteri of gilts with genotype T/T and pictures $\mathbf{f}$ to $\mathbf{h}$ are from sows with genotype $\mathrm{C} / \mathrm{T}$. Note that the uterus horns shown in $\mathbf{d}$ and $\mathbf{e}$ are more voluminous than in $\mathbf{a}, \mathbf{b}$ and $\mathbf{c}$, but less coiled than those in $\mathbf{e}, \mathbf{f}$ and $\mathbf{g}$

contrasted by the significantly negative effect on traits of lean meat growth (lean meat content, belly meat content, loin eye area, loin to fat ratio) and the positively correlated feed conversion ratio. Intramuscular fat content is negatively correlated with lean meat growth and thus positively affected by the BMP15 mutation.

\section{Discussion}

Identifying genetic determinants of subjectively assessed phenotypes, such as gilts' vulvae size, seems hardly feasible. However, comparing the genotypes of seventeen gilts exhibiting relatively small vulvae with those of fertile sows enabled us to identify a distinct region on the $\mathrm{X}$-chromosome to carry a potential causal mutation in a genome-wide association study. The availability of whole-genome sequence information of ancestors of the affected animals enabled us to readily identifying a likely causal variant, i.e. a nonsense mutation in BMP15.

Only eleven of the seventeen animals with apparently small vulvae that we considered as cases in the GWAS turned out to be homozygous for the mutant allele. This finding demonstrates the power of GWAS for identifying genetic causes even of a poorly phenotype, such as vulva size. Several factors affect their appearance. Vulvae are smaller in pre- than in postpubescent gilts, and the age of puberty varies considerably between animals [4]. A more reliable assessment of the vulva size as a possible indicator of follicular development would require the systematic inspection of a larger number postpubescent gilts [5], which was not feasible for the present study. Vulva size was used as an auxiliary characteristic to identify infertile gilts and it is not a reliable indicator for the distinction between fertile and infertile gilts in general. However, it was sufficient for identifying the causal variant underlying the fertility condition in the present study.

BMP15 has fundamental roles in ovarian function. Its actions include (1) promotion of follicle growth and maturation; (2) regulation of the sensitivity of granulosa cells (GC) to follicle stimulation hormone (FSH); (3) prevention of GC apoptosis; (4) promotion of oocyte developmental competence and (5) determination of ovulation quota [6]. Natural mutations of BMP15 cause primary ovarian insufficiency (POI) in women (reviewed by Patiño et al., 2017) [7]). Natural missense and nonsense mutations of ovine BMP15 cause both an

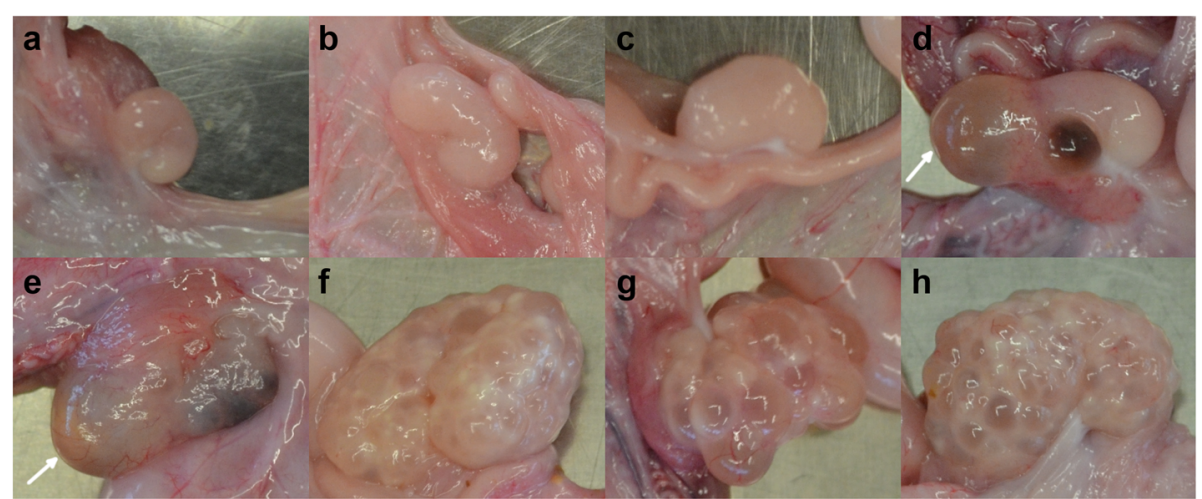

Fig. 3 Ovaries of 8 full sibs at the age of 6 months. Ovaries of fullsib gilts from the mating of a sow with genotype $C / T$ Sscrofa11.1_X:g.44618787C>T (BMP15:R212X) and a boar carrying the T allele. Pictures $\mathbf{a}$ to e show ovaries of gilts with genotype T/T and pictures $\mathbf{f}$ to $\mathbf{h}$ are from sows with genotype $C / T$. The arrows point to cysts 
Table 2 Dosage of the T-allele (causing the nonsense mutation) based on the genotypes of the parents

\begin{tabular}{llll}
\hline & C/C-sow & C/T-sow & C/N-sow \\
\hline C-boar & 0 & 0.5 & $\mathrm{q}_{\mathrm{f}}=0.062$ \\
T-boar & 1 & 1 & 1 \\
N-boar & $\mathrm{q}_{\mathrm{m}}=0.069$ & $\mathrm{q}_{\mathrm{m}}+0.5=0.569$ & $\mathrm{q}_{\mathrm{m}}+\mathrm{q}_{\mathrm{f}}=0.131$
\end{tabular}

$\mathrm{q}_{\mathrm{m}}$ : T allele frequency in boars; $\mathrm{q}_{\mathrm{f}} \mathrm{T}$ allele frequency in sows; $\mathrm{C}$ : wildtype allele; $\mathrm{T}$ : mutant allele; N: allele not known

increased ovulation rate and infertility, depending on the dosage of the mutant allele [3, 8-12]. Notable exceptions are missense mutations of $B M P 15$ in the Grivette and Olkuska sheep breeds, as they do not cause infertility. They increase the ovulation rate and the litter size in a dosage-dependent manner without causing infertility [12]. BMP15 acts through homodimerization of the mature protein and heterodimerization with GDF9 (growth differentiation factor 9), another member of the transforming growth factor $\beta$ (TGF- $\beta$ ) family [13]. Mutations of GDF9 also affect fertility in sheep in the same mode as mutations of $B M P 15[8,14,15]$. Since the GWAS did not show significantly associated SNPs in the GDF9-containing region on chromosome 2, GDF9 was not considered as a candidate in the present study. A Mutation of the bone morphogenetic protein IB receptor $(B M P R 1 B)$, finally, causes the high prolificacy Booroola phenotype [16-18] without a negative effect in the homozygous state.

While mutations of BMP15 critically affect follicular development and ovulation rate in dosage-sensitive manners in the mono-ovulatory human and ovine species, the effects of such mutations seem to be less pronounced in the poly-ovulatory species mouse. BMP15-knockout female mice have minimal ovarian histopathological defects but are subfertile due to a decreased ovulation rate [19]. However, knockdown of $B M P 15$ in the poly-ovulatory species swine completely inhibits ovarian follicular development, leading to infertility [20]. This latter study did not allow to assess the effect of the null allele's heterozygous state on the ovulation rate and litter size. The natural nonsense mutation of BMP15 that we describe in the present study is most likely a null allele as it results in a severely truncated protein (47.5\% are missing) and / or nonsense-mediated mRNA decay. Our data indicate that heterozygosity of a BMP15 mutation also enhances litter size in polyovulatory swine, just as has been amply reported in mono-ovulatory sheep. GDF9 and BMP15 mutations also seem to be more frequent in mothers of dizygotic twins than mothers of single infants or monozygotic twins [21], pointing to the possibility of an increased ovulation rate due to heterozygosity of deleterious variants in the human species as well.

Galloway et al. (2000) [3] set out to explain the paradoxical dosage effect of BMP15 and GDF9 mutations. They hypothesized that $50 \%$ of normal levels of the proteins might reduce granulosa cell mitosis and delay suppressive effects on plasma follicle-stimulating hormone (FSH) concentrations and that the concomitant reduction of the amount of steroid or inhibin would lead to the ovulation of an additional oocyte in monoovulatory species (or additional oocytes in polyovulatory species). McNatty et al. (2009) [22] showed that an earlier acquisition of responsiveness to the luteinizing hormone ( $\mathrm{LH}$ ) by granulosa cells in a higher proportion of follicles accounts for the higher ovulationrate in heterozygous carriers of a BMP15 mutation.

To increase the litter size is an objective of pig breeding. Breeding gilts that are heterozygous for the nonsense mutation of the BMP15 mutation could expedite the breeding for increased litter size. In detail, German Landrace boars carrying the mutation could be mated with German Large White sows. Homozygous female littermates of these boars can be diagnosed by a DNA-test and directed to fattening. All crossbred gilts sired by these boars would be carriers of the mutation. Symptomatic homozygous crossbred progeny would not result in this crossbreeding scheme since German Large White animals do not carry the BMP15 mutation (data not shown). When mated with Piétrain boars, crossbred sows will produce an increased number of piglets suitable for fattening.

The outlined selection scheme to achieve an increased litter size is only advisable if the BMP15 mutation does not negatively affect other economically relevant traits. However, our data reveal a significantly negative effect of the BMP15 mutation on traits of lean meat growth. We did not expect such an effect since the BMP15 gene is expressed exclusively in oocytes, and the protein does not seem to have any other function than to control the development of follicles and ovulation [7, 21]. We assume the p.R212X-mutation in BMP15 to have pleiotropic effects on fertility and lean meat growth. However, it is not possible to distinguish between biological pleiotropy (single causal variant or different causal variants in the same gene) or spurious pleiotropy

Table 3 Number of sows in T-allele dosage groups

\begin{tabular}{lllllll}
\hline & \multicolumn{1}{l}{ T allele dosage } & & & & \\
\cline { 2 - 6 } & $\mathbf{0 . 0 0 0}$ & $\mathbf{0 . 0 6 2}$ & $\mathbf{0 . 0 6 9}$ & $\mathbf{0 . 1 3 1}$ & $\mathbf{0 . 5 0 0}$ & $\mathbf{0 . 5 6 9}$ \\
\hline $\mathbf{N}$ sows & $8400(4156)$ & $9623(9623)$ & $1092(1092)$ & $9969(9969)$ & $1185(1185)$ & $565(565)$ \\
\hline
\end{tabular}

Numbers in parentheses indicate animals with allele dosage derived from the parents' genotypes 
Table 4 Estimated effects of the p.R212X-mutation on economically important traits

\begin{tabular}{|c|c|c|c|c|}
\hline Trait & N sows & Effect \pm std. error & $P$-value & Significance \\
\hline Live-born piglets $(\mathrm{N})$ & 20,549 & $+0.411 \pm 0.021$ & $4.50 \times 10^{-83}$ & ***** \\
\hline Feed conversion ratio $(\mathrm{kg} / \mathrm{kg})$ & 10,072 & $-0.028 \pm 0.004$ & $7.60 \times 10^{-15}$ & $* * * *$ \\
\hline Daily gain (g/day) & 10,072 & $-0.847 \pm 1.684$ & $6.15 \times 10^{-01}$ & \\
\hline Lean meat content (\%) & 10,072 & $-0.889 \pm 0.059$ & $2.50 \times 10^{-51}$ & $* * * *$ \\
\hline Belly meat content $(\%)$ & 10,072 & $-0.906 \pm 0.057$ & $2.21 \times 10^{-56}$ & $* * * *$ \\
\hline Loin eye area $\left(\mathrm{cm}^{2}\right)$ & 10,072 & $-1.216 \pm 0.097$ & $1.12 \times 10^{-35}$ & $* * * *$ \\
\hline Loin to fat ratio $\left(\mathrm{cm}^{2} / \mathrm{cm}^{2}\right)$ & 10,072 & $-0.031 \pm 0.002$ & $1.06 \times 10^{-51}$ & $* * * *$ \\
\hline Carcass length $(\mathrm{cm})$ & 10,072 & $-0.030 \pm 0.045$ & $5.13 \times 10^{-01}$ & \\
\hline Intramuscular fat content (\%) & 10,072 & $0.068 \pm 0.007$ & $6.20 \times 10^{-25}$ & $* * * *$ \\
\hline pH 1 & 10,072 & $0.002 \pm 0.002$ & $1.16 \times 10^{-01}$ & \\
\hline Drip loss (\%) & 10,072 & $-0.005 \pm 0.004$ & $2.16 \times 10^{-01}$ & \\
\hline
\end{tabular}

$N$ sows Number of sows with a breeding value reliability $\geq 40 \%$; Bonferroni corrected significance for eleven tests is $P$-value $\leq 4.5 \times 10^{-03}$. ${ }^{* * * *}$ significant at $P \leq$ $1 \times 10^{-04}$

(different causal variants in different genes in a region of strong LD) momentarily [23]. To clarify the pleiotropic effects, further studies are needed.

When taking the economic weights [24, 25] for significantly affected traits into account, we can assess the effect of the BMP15 mutation economically. Each additional live-born piglet has a monetary value of 3.98 $€$, each $\mathrm{kg}$ less feed consumed per $\mathrm{kg}$ gain $22.70 €$, and each percentage point of lean meat content $1.66 €$, yielding a total monetary effect of the mutant allele of -0.48 $€$ per finisher pig. Thus, using the BMP15 mutation to increase litter size is not advisable, and the eradication of the mutant allele from the German Landrace population, if carefully executed with regard to the genetic diversity, should not cause losses.

\section{Conclusions}

The observation of gilts with atypically small vulvae prompted a genome-wide association study that led to the detection of an associated region on the X-chromosome. The inspection of whole-genome sequencing data allowed us to pinpoint a nonsense mutation of BMP15 (Sscrofa11.1_X:g.44618787C>T, NP_001005155.2:p.R212X) as the most likely causal variant. Like mutations of the ovine $B M P 15$, the porcine mutation affects female fertility in a dosage-dependent manner. Homozygous female carriers of the variant lack proper ovary function and are infertile; heterozygous sows produce +0.41 piglets per litter. Male animals are not afflicted. Thus, our findings show that the BMP15 nonsense mutation has similar effects in the poly-ovulatory species swine, as observed for deleterious BMP15 mutations in the mono-ovulatory species sheep. The negative effect of the mutant allele on lean meat growth precludes using the variant for increasing the litter size by selective breeding. The recommendation is, therefore, to eradicate the $B M P 15$ allele from the German Landrace breed.

\section{Methods \\ DNA extraction and genotyping}

DNA was extracted from tissue samples of affected animals, collected at slaughter with the DNeasy Blood and Tissue Kit (Qiagen, Germany). Genome-wide genotypes of these samples and control animals were obtained with the Illumina Porcine SNP60 BeadChip, using default parameters of Illumina's BeadStudio for genotype calling. The SNPs' chromosomal positions were according to the Sscrofa11.1 assembly [26]. Sanger-sequencing was used to validate the genotypes of the Sscrofa11.1_X: g.44618787C $>\mathrm{T}$ candidate causal variant as derived from next-generation sequencing. Genomic PCR products obtained with primers 5'-CGCCATCAACTTCACCTAGC - 3 (forward) and 5' -TCTGGGAAGAAGTTTGGCCT3 ' (reverse) were sequenced using the BigDye ${ }^{\odot}$ Terminator v1.1 Cycle Sequencing Kit (Life Technologies) on an ABI 3130xl Genetic Analyzer (Life Technologies) instrument. We customized a KASP ${ }^{\mathrm{Tm}}$ genotyping assay (LGC Genomics) for typing the variant at the population level, using 5'-TCACAAGGGGCGCAGGGTTCT A-3' as common PCR primer, 5' -GACACATGAAGCGGAGTC G-3' as primer for the wild type C allele, and 5'-GCTG ACACATGAAGCGGAGTCA-3' as primer for the mutant $\mathrm{T}$ allele.

\section{Genome-wide association study (GWAS)}

We retained Porcine SNP60 BeadChip derived genotypes of SNPs positioned on the autosomes and the Xchromosome if the calling rates were higher than $90 \%$ and the minor allele frequency above $1 \%$ after quality control with PLINK v. 1.9 [27]. The final data set for the GWAS comprised 50,649 SNPs, 17 case-animals, and 
fertile 1818 control-animals (German Landrace herdbook sows with pedigree information), i.e. sows with at least one litter. A linear mixed model assessed the association between a SNP and the phenotype (0, control; 1 , case) by single-locus regression using the GCTA software [28] and the following model:

$$
y=a+b x+g+e,
$$

where $y$ is the phenotype (coded as 1 for affected and 0 for unaffected), $a$ is the mean term, $b$ is the additive effect (fixed effect) of the candidate SNP to be tested for association, $x$ is the SNP genotype indicator variable coded as 0,1 or $2, g$ is the polygenic effect (random effect), i.e., the accumulated effect of all SNPs (as captured by the GRM calculated using all SNPs) and $e$ is the residual. We considered SNPs with $P$-values less than 9.87 $\times 10^{-7}$ as significantly associated (5\% Bonferronicorrected significance threshold for 50,649 independent tests). The inflation factor was calculated using the estlambda function of the R-package GenABEL [29].

\section{Whole-genome sequencing}

The genomes of 42 influential ancestors of two pig populations (22 German Landrace: 14 boars and eight sows, 20 Piétrains: 18 boars and two sows) were sequenced to an average coverage of $12.68 \mathrm{x}$ (minimum: $7.90 \mathrm{x}$, maximum: $16.05 \mathrm{x}$ ). The sire of eight sows with atypically small vulvae had a coverage of $13.95 \mathrm{x}$ (for detailed sequencing information see Additional file 4). Library preparation followed ultrasonic fragmentation (Covaris (50 s, 5\% duty factor)) using the Illumina TruSeq DNA PCR-Free Sample Preparation Kit with an insert size of $350 \mathrm{bp}$. The libraries' sequencing was in the $125 \mathrm{bp}$ paired-end mode on the HiSeq2500 instrument (Illumina, San Diego, USA). The reads were aligned to the reference sequence (Sscrofa11.1) using the Burrow-Wheeler aligner (BWA) [30]. Variants were called with GATK [31] and visualized with the Integrative Genomics Viewer (IGV) [32]. The Ensembl Variant Effect Predictor (VEP) [33] was used to annotate the variants according to the RefSeq (v. 2017_05) annotation of the Sscrofa11.1-assembly.

\section{Mating of animals carrying the mutation and inspection of ovaries and uteri in female offspring}

Two herdbook German Landrace gilts with pedigree information carrying the nonsense-allele of the BMP15: $\mathrm{pR} 212 \mathrm{X}$ variant were acquired and raised on the experimental station Thalhausen of the Technical University of Munich. The gilts exhibited regular estrous cycles and were artificially inseminated at 8 months of age, with the semen of a boar also carrying the mutation. After normal gestation, one sow gave birth to only male piglets that we did not further consider for the study, and the other sow delivered thirteen piglets, ten of them female. Weaning of the litter was at the age of 4 weeks. The ten females stayed in a standard pen under standard rearing conditions until they reached 3 months and were then divided into two groups with five pigs each and further kept under standard conditions. We genotyped the animals at Sscrofa11.1_X:g.44618787C $>$ T with the KASP ${ }^{\mathrm{rm}}$ assay (see above) after blood samples were drawn at the age of 8 weeks and DNA was extracted by proteinase K treatment and the salting-out method. At 6 months of age, eight of the ten female pigs (five with $\mathrm{T} / \mathrm{T}$ - and three with the $\mathrm{C} / \mathrm{T}$-genotype) were slaughtered after gaseous stunning with carbon dioxide. Uteri and ovaries were removed and examined.

\section{Deriving the T-allele's dosage of}

\section{Sscrofa11.1_X:g.44618787C $>T$ in sows without genotype information}

As genotypes were not available for all German Landrace sows in Bavaria with breeding values, we derived genotypes from the parents' genotypes to increase the number of informative animals for studying the effects of the mutation. When taking the X-chromosomal inheritance of the BMP15 mutation (Sscrofa11.1_X: g.44618787C $>\mathrm{T}$ ) into account, the following applies for female progeny: Parents that are $\mathrm{C} / \mathrm{C}$ (sow) and $\mathrm{C}$ (boar) have $\mathrm{C} / \mathrm{C}$-progeny exclusively (dosage of $\mathrm{T}$ equals 0 ); if the mother is $C / T$ and the boar is $C$, the progeny's dosage of $\mathrm{T}$ equals 0.5 . If the boar is $\mathrm{C}$ and the mother is not directly genotyped, i.e., either $\mathrm{C} / \mathrm{T}$ or $\mathrm{C} / \mathrm{C}$ (not $\mathrm{T} / \mathrm{T}$, as this genotype is not compatible with fertility), the dosage of the T-allele in the progeny amounts to the Tallele's frequency in the female population. If the boar's genotype is $\mathrm{T}$, all resulting fertile females are $\mathrm{C} / \mathrm{T}$ (dosage of $\mathrm{T}$ equals 1 ). If the boar has no genotype and the mother is $\mathrm{C} / \mathrm{C}$, the dosage of $\mathrm{T}$ in the progeny corresponds to the T-allele's frequency in the male population. If the mother is $\mathrm{C} / \mathrm{T}$, the resulting dosage of $\mathrm{T}$ in the progeny is 0.5 plus the male T-allele's frequency. Finally, if the boar and the sow lack direct genotype information, i.e., the sow is either $\mathrm{C} / \mathrm{C}$ or $\mathrm{C} / \mathrm{T}$, the female progeny's $\mathrm{T}$-allele dosage is the sum of the male and the female T-allele's frequency.

\section{Estimating the T-allele's effect on breeding values}

We used the linear regression model of the statsmodels package [34] in the Python environment (v. 3.7 [35]) to estimate the effects of the mutant $\mathrm{T}$-allele on breeding values:

$$
y=a+b x+e,
$$

where $y$ is estimated breeding value, $a$ is the mean term, $b$ is the additive effect of the T-allele, $x$ is the T-allele 
dosage $(0.000,0.062,0.069,0.131,0.500,0.569,1.00)$, and $e$ is the residual. Breeding values for the considered traits (see Table 4) were from the routine genetic evaluation for Bavarian pig breeds (Bavarian State Research Centre for Agriculture, Institute of Animal Breeding), estimated with a multiple-trait model using a single-step genomic BLUP method. An effect was considered significant if $P \leq 0.0045$ (the Bonferroni corrected significance level for eleven tests, i.e., breeding values). We considered only breeding values with a reliability of at least $40 \%$.

\section{Supplementary Information}

The online version contains supplementary material available at https://doi. org/10.1186/s12864-020-07343-x.

\section{Additional file 1. \\ Additional file 2. \\ Additional file 3 . \\ Additional file 4}

\begin{abstract}
Abbreviations
BMP15: Bone morphogenetic protein 15; C-boar: Boar hemizygous for the wildtype allele of the BMP15:p.R212X-mutation; C/C-sow: Sow homozygous for the wildtype allele of the BMP15:p.R212X-mutation; C/N-sow: Sow with unknown genotype for the BMP15:p.R212X-mutation; C/T-sow: Sow carrying the BMP15:p.R212X-mutation in the heterozygous state; GWAS: Genome wide association study; N-boar: Boar with unknown genotype for the BMP15:p.R212X-mutation; NM_001005155.2:C.687C>T (BMP15:C687C>T): .C to T substitution at position 687 of porcine BMP15 CDNA, accession number NM_001005155.2; NP_001005155.2:p.R212X (BMP15:p.R212X): nonsense mutation at position 212 of porcine BMP15 protein, accession number NP_001005155.2; SNP: Single nucleotide polymorphism;

Sscrofa11.1_X:g.44618787C>T: .C to T substitution at position 44618787 on X chromosome of Sscrofa11.1 assembly; T-boar: Boar hemizygous for the mutant allele of the BMP15:p.R212X-mutation
\end{abstract}

\section{Acknowledgements}

We thank the owners of the affected animals for communicating their observations.

\section{Authors' contributions}

GF performed molecular-genetic analyses. CW and RF performed next generation sequencing and variant detection. GF, HP, AT and RF analyzed data. JD, GD and KUG provided breeding values and information on affected animals. IR provided genotype data. RF, HP and GF conceived the study. GF and RF wrote the manuscript. All authors have read and approved the manuscript.

\section{Funding}

We acknowledge funding of the projects InGeniS by the Bavarian Ministry of Nutrition, Agriculture and Forestry and FORTiGe (AZ-1300-17) by the Bavarian Research Foundation. The funding bodies played no role in the design of the study, analysis data interpretation and writing the manuscript. Open Access funding enabled and organized by Projekt DEAL.

\section{Availability of data and materials}

All data sets used and analyzed during the current study are available from the corresponding author RF (ruedi.fries@tum.de) on reasonable request and with permission of the Bavarian pig breeding association.

\section{Ethics approval and consent to participate}

Ethics approval was obtained by the Regierung von Oberbayern (Sachgebiet 54) for taking blood samples from female piglets of matings between two herdbook German Landrace gilts carrying the BMP15 variant and a German Landrace insemination boar also carrying the mutation. Approval was also obtained for slaughter after gaseous stunning with carbon dioxide at the age of 6 months for examining the uteri and ovaries. Ethical approval was not necessary otherwise because analyses were performed on existing data and DNA obtained for routine genomic breeding value estimation of the Bavarian pig breeding association.

\section{Consent for publication}

Not applicable.

\section{Competing interests}

$\mathrm{HP}$ is a member of the editorial board of BMC Genomics. All other authors declare that they have no competing interests.

\section{Author details}

${ }^{1}$ Lehrstuhl für Tierzucht, Technische Universität München, Freising, Germany. ${ }^{2}$ Animal Genomics, ETH Zürich, Zürich, Switzerland. ${ }^{3}$ Institut für Tierzucht, Bayerische Landesanstalt für Landwirtschaft, Poing, Germany.

${ }^{4}$ Tierzuchtforschung e. V. München, Poing, Germany.

Received: 13 December 2020 Accepted: 22 December 2020

Published online: 07 January 2021

\section{References}

1. Pailhoux E, Pelliniemi L, Barbosa A, Parma P, Kuopio T, Cotinot C. Relevance of intersexuality to breeding and reproductive biotechnology programs; XX sex reversal in pigs. Theriogenology. 1997;47:93-102.

2. Rousseau S, lannuccelli N, Mercat M-J, Naylies C, Thouly J-C, Servin B, et al. A genome-wide association study points out the causal implication of SOX9 in the sex-reversal phenotype in XX pigs. PLoS One. 2013;8:e79882.

3. Galloway SM, McNatty KP, Cambridge LM, Laitinen MP, Juengel $J$, Jokiranta TS, et al. Mutations in an oocyte-derived growth factor gene (BMP15) cause increased ovulation rate and infertility in a dosage-sensitive manner. Nat Genet. 2000;25:279-83.

4. Knauer MT, Cassady JP, Newcom DW, See MT. Phenotypic and genetic correlations between gilt estrus, puberty, growth, composition, and structural conformation traits with first-litter reproductive measures. J Anim Sci. 2011;89:935-42.

5. Graves KL, Mordhorst BR, Wright EC, Hale BJ, Stalder KJ, Keating AF, et al. Identification of measures predictive of age of puberty onset in gilts. Trans Anim Sci. 2020:4:285-92

6. Persani L, Rossetti R, Di Pasquale E, Cacciatore C, Fabre S. The fundamental role of bone morphogenetic protein 15 in ovarian function and its involvement in female fertility disorders. Hum Reprod Update. 2014;20:869-83.

7. Patiño LC, Walton KL, Mueller TD, Johnson KE, Stocker W, Richani D, et al. BMP15 mutations associated with primary ovarian insufficiency reduce expression, activity, or synergy with GDF9. J Clin Endocrinol Metab. 2017; 102:1009-19.

8. Hanrahan JP, Gregan SM, Mulsant P, Mullen M, Davis GH, Powell R, et al Mutations in the genes for oocyte-derived growth factors GDF9 and BMP15 are associated with both increased ovulation rate and sterility in Cambridge and Belclare sheep (Ovis aries). Biol Reprod. 2004;70:900-9.

9. Bodin L, Di Pasquale E, Fabre S, Bontoux M, Monget P, Persani L, et al. A novel mutation in the bone morphogenetic protein 15 gene causing defective protein secretion is associated with both increased ovulation rate and sterility in Lacaune sheep. Endocrinology. 2007;148:393-400.

10. Martinez-Royo A, Jurado JJ, Smulders JP, Martí IJ, Alabart JL, Roche A, et al. A deletion in the bone morphogenetic protein 15 gene causes sterility and increased prolificacy in rasa Aragonesa sheep. Anim Genet. 2008;39:294-7.

11. Monteagudo LV, Ponz R, Tejedor MT, Laviña A, Sierra I. A 17 bp deletion in the bone morphogenetic protein 15 (BMP15) gene is associated to increased prolificacy in the rasa Aragonesa sheep breed. Anim Reprod Sci. 2009;110:139-46.

12. Demars J, Fabre S, Sarry J, Rossetti R, Gilbert H, Persani L, et al. Genomewide association studies identify two novel BMP15 mutations responsible for an atypical hyperprolificacy phenotype in sheep. PLoS Genet. 2013;9: e1003482

13. Shimasaki S, Moore RK, Otsuka F, Erickson GF. The bone morphogenetic protein system in mammalian reproduction. Endocr Rev. 2004;25:72-101. 
14. Nicol L, Bishop SC, Pong-Wong R, Bendixen C, Holm L-E, Rhind SM, et al. Homozygosity for a single base-pair mutation in the oocyte-specific GDF9 gene results in sterility in Thoka sheep. Reproduction. 2009;138:921-33.

15. Silva BDM, Castro EA, Souza CJH, Paiva SR, Sartori R, Franco MM, et al. A new polymorphism in the growth and differentiation factor 9 (GDF9) gene is associated with increased ovulation rate and prolificacy in homozygous sheep. Anim Genet. 2011;42:89-92.

16. Mulsant $P$, Lecerf F, Fabre $S$, Schibler $L$, Monget $P$, Lanneluc $I$, et al. Mutation in bone morphogenetic protein receptor-IB is associated with increased ovulation rate in Booroola Mérino ewes. Proc Natl Acad Sci U S A. 2001;98: 5104-9

17. Souza CJ, MacDougall C, MacDougall C, Campbell BK, McNeilly AS, Baird DT. The Booroola (FecB) phenotype is associated with a mutation in the bone morphogenetic receptor type 1 B (BMPR1B) gene. J Endocrinol. 2001;169: R1-6.

18. Wilson T, Wu XY, Juengel JL, Ross IK, Lumsden JM, Lord EA, et al. Highly prolific Booroola sheep have a mutation in the intracellular kinase domain of bone morphogenetic protein IB receptor (ALK-6) that is expressed in both oocytes and granulosa cells. Biol Reprod. 2001;64:1225-35.

19. Yan C, Wang P, DeMayo J, DeMayo FJ, Elvin JA, Carino C, et al. Synergistic roles of bone morphogenetic protein 15 and growth differentiation factor 9 in ovarian function. Mol Endocrinol. 2001:15:854-66.

20. Qin Y, Tang T, Li W, Liu Z, Yang X, Shi X, et al. Bone morphogenetic protein 15 knockdown inhibits porcine ovarian follicular development and ovulation. Front Cell Dev Biol. 2019;7:286.

21. Belli M, Shimasaki S. Molecular aspects and clinical relevance of GDF9 and BMP15 in ovarian function. Vitam Horm. 2018;107:317-48.

22. McNatty KP, Heath DA, Hudson NL, Lun S, Juengel JL, Moore LG. Gonadotrophin-responsiveness of granulosa cells from bone morphogenetic protein 15 heterozygous mutant sheep. Reproduction. 2009; 138:545-51.

23. Solovieff N, Cotsapas C, Lee PH, Purcell SM, Smoller JW. Pleiotropy in complex traits: challenges and strategies. Nat Rev Genet. 2013;14:483-95.

24. Zuchtziele. https://www.lfl.bayern.de/itz/schwein/046844/index.php. Accessed 26 Jun 2020

25. Habier D, Götz K-U, Dempfle L. Economic weights of performance traits for sire breeds for the Bavarian pig breeding. Züchtungskunde. 2004;76:307-20.

26. Warr A, Affara N, Aken B, Beiki H, Bickhart DM, Billis K, et al. An improved pig reference genome sequence to enable pig genetics and genomics research. Gigascience. 2020;9:giaa051.

27. Chang CC, Chow CC, Tellier LC, Vattikuti S, Purcell SM, Lee JJ. Secondgeneration PLINK: rising to the challenge of larger and richer datasets. Gigascience. 2015;4:7.

28. Yang J, Lee SH, Goddard ME, Visscher PM. GCTA: a tool for genome-wide complex trait analysis. Am J Hum Genet. 2011;88:76-82.

29. Aulchenko YS, Ripke S, Isaacs A, van Duijn CM. GenABEL: an R library for genome-wide association analysis. Bioinformatics. 2007;23:1294-6.

30. Li H, Durbin R. Fast and accurate short read alignment with burrowswheeler transform. Bioinformatics. 2009;25:1754-60.

31. McKenna A, Hanna M, Banks E, Sivachenko A, Cibulskis K, Kernytsky A, et al. The genome analysis toolkit: a MapReduce framework for analyzing nextgeneration DNA sequencing data. Genome Res. 2010;20:1297-303.

32. Robinson JT, Thorvaldsdóttir H, Winckler W, Guttman M, Lander ES, Getz G, et al. Integrative genomics viewer. Nat Biotechnol. 2011;29:24-6.

33. McLaren W, Gil L, Hunt SE, Riat HS, Ritchie GRS, Thormann A, et al. The Ensembl variant effect predictor. Genome Biol. 2016;17:122.

34. Seabold S, Perktold J. Statsmodels: Econometric and Statistical Modeling with Python, Proceedings of the 9th Python in Science Conference; 2010. p. 92-6.

35. van Rossum G. Python library reference. 1995. https://ir.cwi.nl/pub/5009. Accessed 20 Jun 2020

\section{Publisher's Note}

Springer Nature remains neutral with regard to jurisdictional claims in published maps and institutional affiliations.

\section{Ready to submit your research? Choose BMC and benefit from:}

- fast, convenient online submission

- thorough peer review by experienced researchers in your field

- rapid publication on acceptance

- support for research data, including large and complex data types

- gold Open Access which fosters wider collaboration and increased citations

- maximum visibility for your research: over $100 \mathrm{M}$ website views per year

At BMC, research is always in progress.

Learn more biomedcentral.com/submissions 